\title{
AV Block Second Degree by ECG Finding
}

National Cancer Institute

\section{Source}

National Cancer Institute. AV Block Second Degree by ECG Finding. NCI Thesaurus. Code C62016.

An electrocardiographic finding of intermittent failure of atrial electrical impulse conduction to the ventricles. This is manifest on the ECG by regular P waves which intermittently are not followed by QRS complexes. (CDISC) 